\title{
Postprandial glycaemic and insulinaemic responses to GM-resistant starch-enriched rice and the production of fermentation-related $\mathrm{H}_{2}$ in healthy Chinese adults
}

\author{
Min Li, Jian-Hua Piao, Yuan Tian, Wei-Dong Li, Ke-Ji Li and Xiao-Guang Yang* \\ Institute of Nutrition and Food Safety, Chinese Center for Disease Control and Prevention, 29 Nan Wei Road, Xuanwu District, \\ Beijing 100050, People's Republic of China
}

(Received 21 May 2009 - Revised 3 September 2009 - Accepted 12 October 2009 - First published online 24 November 2009)

Consumption of resistant starch (RS)-enriched foods is associated with decrease in the postprandial glycaemic and insulinaemic responses, accompanied by the production of fermentation-related gases in the large bowel. The present study aimed to determine the postprandial glycaemic and insulinaemic responses to the GM RS-enriched rice and the fermentation-related production of $\mathrm{H}_{2}$ in young and healthy Chinese adults. A total of sixteen young adults (nine men and seven women) were recruited and divided into three groups. Their postprandial glycaemic and insulinaemic responses to $40 \mathrm{~g}$ glucose, carbohydrates of RS or wild-type (WT) rice were tested by a crossover model with a washout period of $7 \mathrm{~d}$. The concentrations of blood glucose and insulin as well as breath $\mathrm{H}_{2}$ were measured before and after food intake. Although the mean concentrations of fasting blood glucose, insulin and breath $\mathrm{H}_{2}$ were similar, consumption of the RS rice significantly decreased the values of glycaemic index (GI) and insulin index (II), as compared with the intake of WT rice (48.4 (SEM 21.8) v. 77.4 (SEM 34.9) for GI, 34.2 (SEM 18.9) v. 54.4 (SEM 22.4) for II, $P<0.05)$, respectively. Conversely, intake of the RS rice meal significantly elevated the concentrations of breath $\mathrm{H}_{2}$, as compared with WT rice (38.9 (SEM 17.6) v. 10.5 (SEM 3.7) parts per million for peak levels of breath $\mathrm{H}_{2}, P<0.05$ ) through a period of 16-h tests. Consumption of the GM RS-enriched rice meal decreased the postprandial glycaemic and insulinaemic responses and promoted RS fermentation-related production of $\mathrm{H}_{2}$ in the large bowel of young and healthy Chinese adults.

Resistant starch: GM rice: Glucose: Insulin: Breath hydrogen

Resistant starch (RS) is the sum of starch and products of starch hydrolysis, which are not absorbed in the small intestine of healthy individuals ${ }^{(1,2)}$. RS, like dietary fibre, can pass through the small intestine and directly enter into the large bowel where RS is fermented by anaerobic bacteria ${ }^{(3-8)}$. Consumption of RS-enriched foods has been shown to decrease the postprandial glycaemic and insulinaemic responses in some ethnic populations ${ }^{(9,10)}$. Chinese usually consume high levels of carbohydrates, especially for rice, almost every day. Whether their consumption with RS-enriched foods can reduce their glycaemic and insulinaemic responses is little explored. Furthermore, continual consumption of high-energy of foods, particularly for easily digestible starches, can impair glucose metabolism and is associated with obesity and insulin resistance, which are risk factors for the development of CVD and diabetes ${ }^{(11,12)}$. The characterisation of glycaemic and insulinaemic responses to regular and RS-enriched foods will be of great significance for education and prevention of obesity-related diseases in China. Rice is probably the most important staple crop for many people to obtain energy and support their lives in the world because of its high carbohydrate. Regular rice (wild-type rice, WT) contains very low levels of RS, particularly after extensive processing ${ }^{(13)}$. Great effort has been taken to generate RS-enriched foods, such as transgenic crops, for human consumers in the world. Although the effect of maize and potato intake on glycaemic and insulinaemic responses in human subjects has been extensively studied $^{(9,14-16)}$, little is known about the safety and physiological effect of RS-enriched rice consumption, especially with transgenic rice. Assurance of its safety and physiological benefits is a critical base for human consumption. Consumption of RS-enriched foods has shown beneficial effects on reducing postprandial glucose and insulin responses in people with either normal glucose tolerance or impaired glucose tolerance $e^{(9,10,17,18)}$. Continual intake of RS can also promote the production of high levels of SCFA, such as acetic, propionic and butyric acids, in the large bowel ${ }^{(3-8)}$. Furthermore, fermentation of RS also produces high levels of different gases, $\mathrm{CO}_{2}$, $\mathrm{CH}_{4}$ and $\mathrm{H}_{2}$, which can be excreted in breath. However, little is known about whether consumption with the GM RS-enriched rice can promote the production of high levels of $\mathrm{H}_{2}$ in healthy Chinese adults. Notably, the levels of breath $\mathrm{H}_{2}$ are well correlated with the amount of $\mathrm{H}_{2}$ produced in the large bowel ${ }^{(19-22)}$. Accordingly, the determination of breath $\mathrm{H}_{2}$ can be useful for the evaluation of whether the GM RS-enriched rice can be fermented in the large bowel.

Abbreviations: AUC, area under the curve; GI, glycaemic index; RS, resistant starch; WT, wild-type.

* Corresponding author: Xiao-Guang Yang, fax +86010 83132808, email xgyangcdc@vip.sina.com 
The present study aimed to evaluate the postprandial glycaemic and insulinaemic responses to GM RS-enriched rice and determined whether consumption of this type of rice could promote the production of colonic fermentation-related $\mathrm{H}_{2}$ in young and healthy Chinese adults.

\section{Subjects and methods}

\section{Subjects}

Nine voluntary men of 23-26 years of age (24.3 (SEM 1.0)) and seven women of 24-26 years of age (24.6 (SEM 0.7)) were recruited for the present study. All subjects were firstly subjected to routine medical examination. All participants met the criteria of eligibility: BMI of $18-24 \mathrm{~kg} / \mathrm{m}^{2}$; normal ranges of fasting plasma glucose, total cholesterol, TAG, HDL-cholesterol, total bilirubin, urea, alanine aminotransferase and blood cell counting; without history of smoking, diabetes and other chronic metabolic or gastrointestinal diseases; no recent infectious diseases, surgery or antibiotic therapy within 8 weeks. After the routine medical examination, eligible individuals were subjected to the oral glucose tolerance test. They were orally administrated with $50 \mathrm{~g}$ glucose in $300 \mathrm{ml}$ water, and their venous blood samples were collected at $0,15,30,45,60,90,120,180$ and $240 \mathrm{~min}$ post-glucose challenge. Subjects agreed to avoid consuming any $\mathrm{H}_{2}$-produced foods, such as legumes and dairy products, high-fibre food, alcohol, beverages and others, for $24 \mathrm{~h}$ before their study session. Before each study session, subjects recorded their consumption of foods for $24 \mathrm{~h}$. The present study was conducted according to the guidelines laid down in the Declaration of Helsinki, and all procedures involving human subjects were approved by the Ethical Committee of Institute for Nutrition and Food Safety, Chinese Center for Disease Control and Prevention. Written informed consent was obtained from all subjects.

\section{Rice samples}

The RS and WT rice was provided from the Key Laboratory of Education Ministry for Plant Functional Genomics, Agricultural College of Yangzhou University (Jiangsu Province, China). The RS-enriched rice was generated by transgenic expression of the antisense complementary to the transcript of the starch-branching enzyme gene in an indica rice (Oryza sativa L. cv. Te-Qing), which is a rice cultivar with a high yield in southern China. Accordingly, the transgenic rice produced high levels of amylose and RS because of inhibition of starch-branching enzyme, which is critical for the synthesis of amylopectin. The RS and WT rice was grown in adjoining fields under the same environmental conditions and field management. After harvesting and paddy hulling, the RS and WT rice samples were obtained. Following milling, the contents of proteins (Chinese standard GB 5009.5-2003), fat (Chinese standard GB 5009.6-2003), fibre (Chinese standard GB 5009.10-2003), ash (Chinese standard GB 5009.4-2003) and moisture (Chinese standard GB 5009.3-2003) in the RS and WT rice were determined in Table 1. Total carbohydrate was equal to $100 \%-$ $(\%$ protein $+\%$ fat $+\%$ ash $+\%$ water $)$. The contents of $\mathrm{RS}$ in RS and WT rice were analysed using a commercially
Table 1. The main nutrients profile of the resistant starch (RS) and wild-type (WT) rice test meals (g)

(Mean values and with their standard errors)

\begin{tabular}{lrrrrr}
\hline & \multicolumn{2}{c}{ RS rice } & & \multicolumn{2}{c}{ WT rice } \\
\cline { 2 - 3 } \cline { 6 - 6 } Samples & Mean & SEM & & Mean & SEM \\
\hline RS & 8.05 & 0.23 & & 0.97 & 0.14 \\
Protein & 6.12 & 0.05 & & 4.67 & 0.07 \\
Fat & 0.71 & 0.01 & & 0.18 & 0.01 \\
Ash & 0.52 & 0.00 & & 0.24 & 0.00 \\
Fibre & 0.34 & 0.00 & & 0.11 & 0.01 \\
Carbohydrate & 39.82 & 0.08 & & 39.84 & 0.05 \\
\hline
\end{tabular}

available kit (RSTAR11/02, Megzyme, Ireland), according to the manufacturer's instructions.

\section{Experimental design and procedure}

Individuals' postprandial glycaemic and insulinaemic responses to $40 \mathrm{~g}$ glucose, $40 \mathrm{~g}$ carbohydrate of RS or WT rice meal were tested by a crossover study with a washout period of 1 week. The dose was based on our preliminary data and the maximum amount for most subjects to consume comfortably within $10 \mathrm{~min}$ without intolerance symptoms like diarrhoea, nausea, abdominal cramping, distention and flatulence. Nine healthy men and seven women were randomly divided into three groups (three men and two to three women per group) and tested simultaneously. They consumed one of the $40 \mathrm{~g}$ glucose, $40 \mathrm{~g}$ carbohydrate of RS and WT rice meal in $300 \mathrm{ml}$ water. The WT and RS rice were cooked for rice meal. One week later, they were administrated with the second type of food and after another week, they were provided with the third type of food. Individual subjects arrived at the study site between 06.00 and 06.30 hours. After resting for $30 \mathrm{~min}$, their temperature, heart and respiratory rates were measured. Individuals were inserted with a catheter into the antecubital vein by a registered nurse. Their blood samples were collected and breath $\mathrm{H}_{2}$ was tested as the baseline values. At 07.00 hours, those subjects consumed individual food within $10 \mathrm{~min}$. Their blood samples $(2 \mathrm{ml})$ were collected at $0,15,30,45,60,90,120,180$ and $240 \mathrm{~min}$ post-food intake and subjected to $\mathrm{H}_{2}$ breath tests for the indicated time points. Subjects did not consume water for the first $2 \mathrm{~h}$ and then permitted to consume $150 \mathrm{ml}$ water in the second $2 \mathrm{~h}$. They were provided a special dinner on the day before testing, lunch and dinner after the last blood collection (5 and $11 \mathrm{~h}$ after the beginning of experiments) with little $\mathrm{H}_{2}$-producing foods. The amount and kind of foods individuals consumed were recorded. The subjects were requested to consume an equal amount of the same kind of foods at lunch and dinner when they participated in testing for the second and third type of foods.

\section{Analysis of plasma glucose and insulin}

The collected blood samples in grey-top BD Vacutainer blood tubes (special for blood glucose test) were centrifuged at $3000 \mathrm{~g}$ for $15 \mathrm{~min}$ at room temperature. The plasma was collected and stored at $-20^{\circ} \mathrm{C}$ for less than $3 \mathrm{~d}$ for analysis, 
which did not significantly change the value of plasma glucose in the present preliminary studies. The concentrations of plasma glucose for individual subjects were measured in duplicate using an automatic spectrophotometric analyzer (Vitalab Selectra E, Holland) as per the glucose oxidase method. The glycaemic index (GI) was calculated based on the incremental area under the curve (AUC) of $4 \mathrm{~h}$ blood glucose measurements using the trapezoidal rule and baseline value as the reference, as previously described ${ }^{(23,24)}$. Any area below the baseline was ignored. GI was calculated by using the following equation: $\mathrm{GI}=(\mathrm{AUC}$ value of the tested rice meal/AUC value of the reference glucose meal) $\times 100$. The levels of plasma insulin for individuals were analysed in duplicate using a commercial RIA kits (North Institute of Biological Technology Corporation, Beijing, China), according to the manufacturer's instructions. Insulin index for individuals was calculated using the same equation based on the AUC values of corresponding plasma insulin.

\section{Hydrogen breath test}

$\mathrm{H}_{2}$ breath tests for individual subjects were performed at 0 and $3 \cdot 5-16 \mathrm{~h}$ post-food consumption with a half-hour interval between 3.5 and $14 \mathrm{~h}$ and 1 -h interval between 14 and $16 \mathrm{~h}$ on a portable breath $\mathrm{H}_{2}$ analyser (HHBT-01, Headway Biotechnology Corporation, Shenzhen, Guangdong Province, China). Before testing, the breath $\mathrm{H}_{2}$ analyser was calibrated with standard gas (118 parts per million). During the period of 16-h $\mathrm{H}_{2}$ breath tests, the subjects were instructed to maintain awake and quiet without intensive activity.

\section{Statistical analysis}

Results were expressed as means with their standard errors. Differences in glucose, insulin and $\mathrm{H}_{2}$ responses to different types of foods were analysed using the Wilcoxon test, and the baseline values of individuals were used as their own controls. All statistical analyses were performed with the Statistical Analysis Systems 9.1 software (SAS Inc., Cary, NC, USA). A value of $P<0.05$ was considered statistically significant.

\section{Results}

To test postprandial glycaemic and insulinaemic responses to the GM RS-enriched rice, a group of young and healthy adults were recruited and randomly divided into three groups. During the study period of 3 weeks, they consumed once with each of $40 \mathrm{~g}$ glucose, $40 \mathrm{~g}$ carbohydrate of RS or WT rice in the morning with an interval of 1 week. There was no single uncomfortable complaint after eating any of the foods in this population. Before they consumed each type of meal, their fasting blood glucose concentrations were measured. Their baseline glucose concentrations before intake of each type of foods were similar (4.7 (SEM 0.3) $v$. 4.6 (SEM 0.4) v. 4.7 (SEM 0.3) mmol/l, $P>0.05$ ), respectively. Following each type of meal, the concentrations of blood glucose were determined for $4 \mathrm{~h}$ (Fig. 1). The concentrations of blood glucose, in response to RS, WT rice or glucose intake, increased rapidly, reached at the peak $30 \mathrm{~min}$ after intake and then gradually declined to the baseline

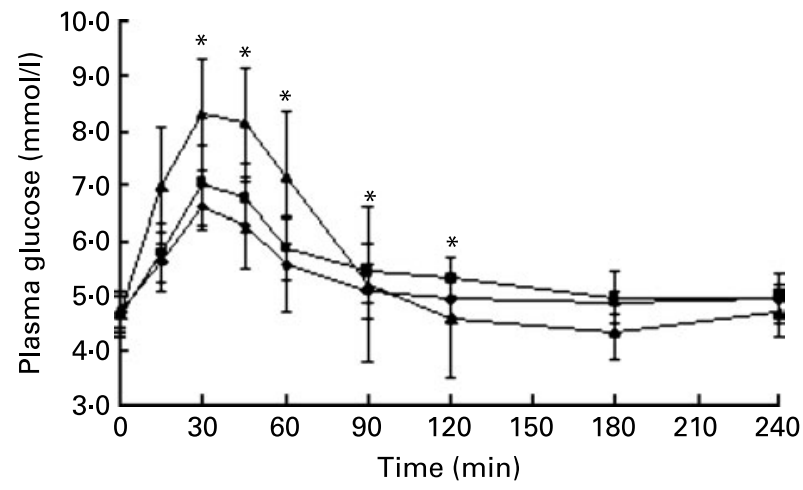

Fig. 1. Analysis of the postprandial glycaemic responses in healthy Chinese adults. Young and healthy Chinese adults ( $n$ 16) were fasted overnight and consumed one type of the resistant starch (RS), wild-type (WT) rice and glucose meals. Their plasma glucose levels were measured before and after each type of foods at indicated time points. Data shown are the mean values with their standard errors of plasma glucose of all subjects after intake of each type of foods through the testing period of $4 \mathrm{~h}$. Values of plasma glucose after the intake of the RS rice $v$. WT rice was determined by the Wilcoxon test $\left({ }^{\star} P<0 \cdot 05\right)$. $\bullet$, RS rice; $\boldsymbol{\square}$, WT rice; $\boldsymbol{\Lambda}$, glucose.

concentrations near $180 \mathrm{~min}$ after each meal. The highest levels of blood glucose after consuming RS rice (6.8 (SEM $0.4) \mathrm{mmol} / \mathrm{l}$ ) were significantly lower than that with WT rice (7.2 (SEM 0.6) mmol/l, $P<0.05$ ), although both values were significantly lower than that of glucose intake. Furthermore, the value of AUC for the RS rice meal was significantly smaller than that for the WT rice meal $(P<0.05)$, particularly at 1 , $1 \cdot 5,2$ and $4 \mathrm{~h}$ post-intake of meals. Importantly, the GI for the RS rice meal (48.4 (SEM 21.8)) was lower than of the WT rice meal (77.4 (SEM 34.9), $P<0.05$ ). Together, these data indicated that consumption of RS-enriched rice reduced postprandial glycaemic responses in young and healthy Chinese adults. Insulin is a critical regulator for glucose metabolism. To determine the impact of RS rice meal on the production of insulin, the concentrations of plasma insulin for individual subjects were measured before and after consuming each type of foods (Fig. 2). The mean baseline insulin concentrations before the RS, WT rice or glucose intake were similar (6.7 (SEM 2.3) v. 6.8 (SEM 2.7) v. 6.1 $($ SEM 1.5$\left.) \times 10^{-6} \mathrm{IU} / \mathrm{ml}, P>0.05\right)$, respectively. The highest concentrations of plasma insulin were detected $45 \mathrm{~min}$ after food intake and gradually declined near to the baseline levels $4 \mathrm{~h}$ after consuming foods. The concentrations of plasma insulin in subjects with the RS rice were significantly lower than that with WT rice at 45, 60, 90 and 120 min postfood intake, although their values were significantly lower than that with glucose intake. The values of insulin AUC at $1 \cdot 5,2$ and $4 \mathrm{~h}$ post-intake of the RS rice were significantly reduced, as compared with that after WT rice. After adjusting to the reference glucose $(100 \%)$, the mean value of insulin index in subjects with the RS rice meal (34.2 (SEM 18.9)) was significantly lower than that with the WT rice meal (54.4 (SEM 22.4), $P<0 \cdot 05$ ). Collectively, consumption of RS-enriched rice reduced postprandial insulinaemic responses in those subjects.

Consumption of RS-enriched foods is usually associated with the production of large amount of SCFA, accompanied by higher levels of gases, such as $\mathrm{CO}_{2}, \mathrm{CH}_{4}$ and $\mathrm{H}_{2}$ from the fermentation in the large bowel. To test the effect of 


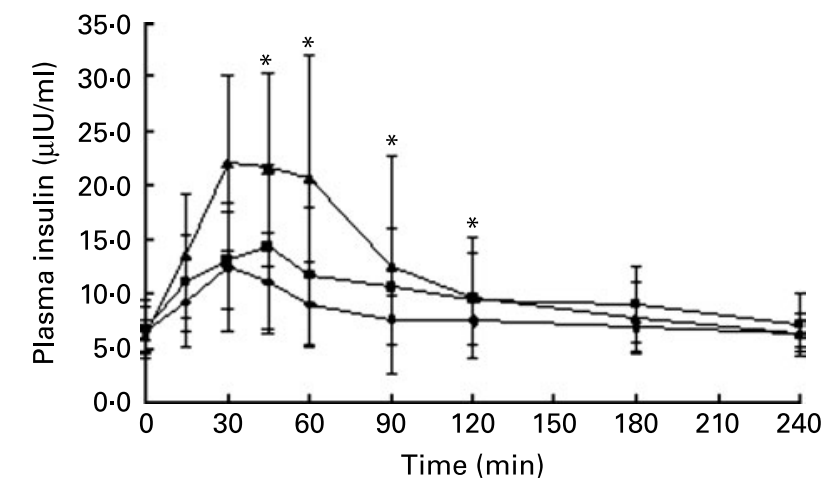

Fig. 2. Analysis of the postprandial insulinaemic responses in healthy Chinese adults. The levels of plasma insulin were measured before and after intake of each type of foods at indicated time points. Data are expressed as the mean values with their standard errors of plasma insulin of all subjects ( $n$ 16) after intake of each type of foods through the testing period of $4 \mathrm{~h}$. Values of plasma insulin after the intake of the resistant starch (RS) rice $v$. wild-type (WT) rice was determined by the Wilcoxon test $\left({ }^{\star} P<0.05\right)$.

$\bullet$, RS rice; $\boldsymbol{\square}, \mathrm{WT}$ rice; $\boldsymbol{\Delta}$, glucose.

RS-enriched rice consumption on the fermentation-related gas production, the levels of breath $\mathrm{H}_{2}$ by individual subjects after the RS and WT rice were characterised by $\mathrm{H}_{2}$ breath tests over a period of $16 \mathrm{~h}$ (Fig. 3). There was no significant difference in the baseline levels of breath $\mathrm{H}_{2}$ before the intake of RS and WT rice. In contrast, the levels of breath $\mathrm{H}_{2}$ after the RS rice were remarkably higher, as compared with that after the WT rice $(P<0 \cdot 05)$. The levels of $\mathrm{H}_{2}$ significantly increased at $5 \mathrm{~h}$ post the RS rice, reached the highest level near $7 \mathrm{~h}$ and flattened until $14 \mathrm{~h}$, followed by declining slightly. The peak levels of breath $\mathrm{H}_{2}$ after the RS rice meal (38.9 (SEM 17.6) parts per million) were significantly higher than after the WT rice (10.5 (SEM 3.7) parts per million, $P<0.05)$. Thus, consumption of RS-enriched rice promoted high levels of breath $\mathrm{H}_{2}$ in young and healthy Chinese adults.

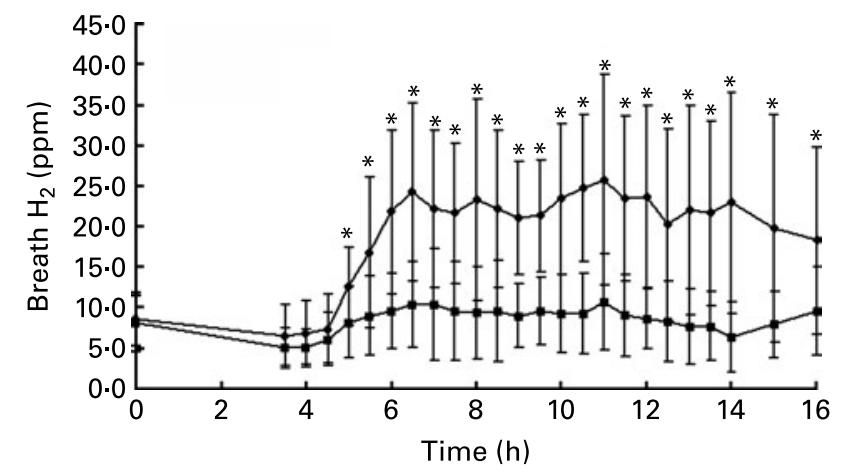

Fig. 3. Determination of breath $\mathrm{H}_{2}$ in healthy Chinese adults. The levels of breath $\mathrm{H}_{2}$ were measured by the breath $\mathrm{H}_{2}$ test before and after RS or WT rice meal at indicated time points. Data shown are the mean levels with their standard errors of breath $\mathrm{H}_{2}$ of all subjects ( $n$ 16) after intake of resistant starch (RS) or wild-type (WT) rice meal through the testing period of $16 \mathrm{~h}$. Values of breath $\mathrm{H}_{2}$ after intake of the RS rice $v$. WT rice was determined by the Wilcoxon test $\left({ }^{\star} P<0.05\right)$. $\diamond$, RS rice; $\mathbf{a}$, WT rice; ppm, parts per million.

\section{Discussion}

In the present study, we determined the postprandial glycaemic and insulinaemic responses to the GM RS-enriched rice and WT rice in young and healthy Chinese adults. In comparison with intake of WT rice or glucose meal, consumption of $40 \mathrm{~g}$ carbohydrates of RS rice meal significantly reduced the values of postprandial glycaemic and insulinaemic responses. Although the kinetics of blood glucose responses were similar after each type of meals, the highest concentrations of glucose, AUC and GI after RS rice meal were significantly lower than that of WT rice or glucose meal. Notably, although those subjects only consumed about $8 \mathrm{~g}$ RS, the dynamics of glucose responses were similar to those who consumed high doses of $\mathrm{RS}^{(18,25)}$. Similar patterns of insulinaemic responses were also observed in this group of Chinese adults. These lower glycaemic and insulinaemic responses to GM RS-enriched rice in Chinese adults were consistent with previous observations in other ethnical populations ${ }^{(26-29)}$. Therefore, consumption of RS-enriched rice, regardless of whether it was GM, mitigated the postprandial glycaemic and insulinaemic responses in young and healthy Chinese adults. These effects indicated that consumption of RS rice meal produced lower levels of absorbable glucose, which stimulated low levels of insulin secretion.

Consumption of RS-enriched foods usually promotes the production of high levels of $\mathrm{H}_{2}, \mathrm{CH}_{4}$ and $\mathrm{CO}_{2}$ because the undigested RS usually enters into the colon where the RS is fermented by anaerobic bacteria ${ }^{(3-8)}$. We characterised the breath $\mathrm{H}_{2}$ after intake of RS and WT rice by the $\mathrm{H}_{2}$ breath test and found that very low levels of $\mathrm{H}_{2}$ were detected after WT rice meal. In contrast, significantly higher levels of $\mathrm{H}_{2}$ were observed after RS rice meal.

These data further indicated that the majority of RS had escaped the digestion in the intestine and entered into the large bowel, in which the RS rice was fermented by anaerobic bacteria in those subjects. Importantly, high levels of gases are usually accompanied by high levels of SCFA production in the large bowel. It is possible that consumption of RS-enriched rice may also promote high levels of SCFA production in those subjects. Previous studies have shown that those SCFA, particularly for acetic, propionic and butyric acids, can lower caecal and faecal $\mathrm{pH}^{(30,31)}$ and promote electrolyte and fluid absorption ${ }^{(32)}$, which assists in the prevention of diarrhoea. The butyrate may promote the growth of colonocytes $^{(10,33,34)}$, but inhibit tumour growth ${ }^{(35-37)}$. SCFA can also change residential bacterial colonies in the large bowel, benefiting the body's health. Therefore, consumption of GM RS-enriched rice may also have beneficial effect on the health of the large bowel. However, whether what types and how much SCFA can be produced by consumption of GM $\mathrm{RS}$-enriched rice in human remain to be further determined.

Unlike many studies of RS-enriched maize origin using ${ }^{13} \mathrm{CO}_{2}{ }^{(38,39)}$, we chose $\mathrm{H}_{2}$ as an indicative gas of $\mathrm{RS}$ fermentation. The similar kinetics and levels of $\mathrm{H}_{2}$ suggest that this method is feasible and reasonable for the assessment of $\mathrm{H}_{2}$ from the fermentation of RS-enriched rice in human subjects. Notably, some subjects showed higher levels of baseline $\mathrm{H}_{2}$, which might be due to the residual accumulation of $\mathrm{H}_{2}$ in the colon. We observed that this high baseline $\mathrm{H}_{2}$ declined within the first few hours, near the real basal level $3.5 \mathrm{~h}$ 
after the beginning of the test, consistent with a previous report ${ }^{(40)}$. Conceivably, the values of $\mathrm{H}_{2}$ at $3.5 \mathrm{~h}$ post-food intake may represent the true baseline level of breath $\mathrm{H}_{2}$. In addition, we continued to test breath $\mathrm{H}_{2}$ for $16 \mathrm{~h}$, which was longer than $12 \mathrm{~h}$ commonly used ${ }^{(38,41)}$, because the levels of breath $\mathrm{H}_{2} 12 \mathrm{~h}$ after the RS rice meal were still higher than that of control with WT rice. This longer effect of the RS rice intake on the production of $\mathrm{H}_{2}$ may be because of unique genetic background of Chinese. Alternatively, this may be attributed to the GM RS-enriched rice that was slow to be fermented. Nevertheless, prolongation of the breath $\mathrm{H}_{2}$ test to $16 \mathrm{~h}$ may be better to measure the fermentation of RS-enriched foods, particularly for the GM RS-enriched rice.

In summary, our data indicated that consumption of the GM RS-enriched rice reduced the postprandial glycaemic and insulinaemic responses, accompanied by producing high levels of the breath $\mathrm{H}_{2}$ in young and healthy Chinese adults. The present findings suggest that consumption of the RS rice may be beneficial for human health. Further studies are needed to determine the safety and beneficial effects of long-term consumption of the GM RS-enriched rice.

\section{Acknowledgements}

We thank the Key Laboratories of Plant Functional Genomics of the Ministry of Education in Agricultural College of Yangzhou University for providing the GM RS-enriched and wildtype rice samples. The present study was supported by the research grant (2007CB109207) from the Ministry of Science and Technology of the People's Republic of China (973 programme). We thank all volunteers for their understanding, cooperation and support in the present study. The authors' responsibilities were as follows: M. L. participated in the design of the experiment, the data collection, data analysis and writing of the manuscript; J.-H. P. assisted with the data collection and analysis; Y. T. participated in the design of the experiment, data collection and data analysis; W.-D. L. participated in the design of the experiment and assisted with the data analysis and the drafting of the manuscript; X.-G. Y. participated in the design of the experiment, guidance during all aspect of the experimental protocol, data analysis and writing of the manuscript. K.-J. L. assisted with the coordination of the field experiment and the data collection. All of the authors participated in a critical review and in the final approval of the manuscript. None of the authors had a personal or financial conflict of interest.

\section{References}

1. Englyst HN, Kingman SM \& Cummings JH (1992) Classification and measurement of nutritionally important starch fractions. Eur J Clin Nutr 46, S33-S50.

2. EURESTA (1992) Resistant starch. Proceedings of the 2nd Plenary Meeting of EURESTA: European FLAIR-Concerted Action No. 11 on physiological implications of the consumption of resistant starch in man. Eur J Clin Nutr 46, S1-S148.

3. Topping DL \& Clifton PM (2001) Short-chain fatty acids and human colonic function: roles of resistant starch and nonstarch polysaccharides. Physiol Rev 81, 1031-1064.

4. Brouns F, Kettlitz B \& Arrigoni E (2002) Resistant starch and 'the butyrate revolution'. Food Sci Technol Int 13, 251-261.
5. Hijova E \& Chmelarova A (2007) Short chain fatty acids and colonic health. Bratisl Lek Listy 108, 354-358.

6. Annison G, Illman RJ \& Topping DL (2003) Acetylated, propionylated or butyrylated starches raise large bowel shortchain fatty acids preferentially when fed to rats. J Nutr 133, 3523-3528.

7. Henningsson AM, Bjorck IM \& Nyman EM (2002) Combinations of indigestible carbohydrates affect short-chain fatty acid formation in the hindgut of rats. J Nutr 132, 3098-3104.

8. Cummings JH \& Macfarlane GT (1991) The control and consequences of bacterial fermentation in the human large intestine. J Appl Bacteriol 70, 443-459.

9. Behall KM, Hallfrisch JG, Scholfield DJ, et al. (2006) Consumption of both resistant starch and beta-glucan improves postprandial plasma glucose and insulin in women. Diabetes Care 29, 976-981.

10. Park OJ, Kang NE, Chang MJ, et al. (2004) Resistant starch supplementation influences blood lipid concentrations and glucose control in overweight subjects. J Nutr Sci Vitaminol 50, 93-99.

11. Jeppesen J, Schaaf P, Jones C, et al. (1997) Effects of low-fat, high-carbohydrate diets on risk factors for ischemic heart disease in postmenopausal women. Am J Clin Nutr 65, 1027-1033.

12. Coutinho M, Gerstein HC, Wang Y, et al. (1999) The relationship between glucose and incident cardiovascular events. A metaregression analysis of published data from 20 studies of 95,783 individuals followed for 12.4 years. Diabetes Care 22, 233-240.

13. Zhang WW, Bi JC \& Yan XY (2007) In vitro measurement of resistant starch of cooked milled rice and physico-chemical characteristics affecting its formation. Food Chem 105, $462-468$.

14. Le Leu RK, Brown IL, Hu Y, et al. (2007) Effect of dietary resistant starch and protein on colonic fermentation and intestinal tumourigenesis in rats. Carcinogenesis 28, 240-245.

15. Robertson MD, Bickerton AS, Dennis AL, et al. (2005) Insulin-sensitizing effects of dietary resistant starch and effects on skeletal muscle and adipose tissue metabolism. Am J Clin Nutr 82, 559-567.

16. Hedemann MS \& Knudsen KE (2007) Resistant starch for weaning pigs - effect on concentration of short chain fatty acids in digesta and intestinal morphology. Livestock Sci 108, $175-177$.

17. Higgins JA (2004) Resistant starch: metabolic effects and potential health benefits. J AOAC Int 87, 761-768.

18. Behall KM \& Hallfrisch J (2002) Plasma glucose and insulin reduction after breads varying in amylose content. Eur J Clin Nutr 56, 913-920.

19. Levitt MD (1969) Production and excretion of $\mathrm{H}_{2}$ gas in man. $N$ Engl J Med 81, 122-127.

20. Wilkens LR, Le Marchand L, Harwood P, et al. (1994) Use of breath $\mathrm{H}_{2}$ and methane as markers of colonic fermentation in epidemiological studies: variability in excretion. Cancer Epidemiol Biomarkers Prev 3, 149-153.

21. Bond JH \& Levitt MD (1972) Use of pulmonary $\mathrm{H}_{2}\left(\mathrm{H}_{2}\right)$ measurements to quantitate carbohydrate absorption: study of partially gastrectomized patients. J Clin Invest 51, 1219-1225.

22. Tormo R, Bertaccini A, Conde $\mathrm{M}$, et al. (2001) Methane and $\mathrm{H}_{2}$ exhalation in normal children and in lactose malabsorption. Early Human Dev 65, S165-S172.

23. Wolever TM, Jenkins DJ, Jenkins AL, et al. (1991) The glycemic index: methodology and clinical implications. Am J Clin Nutr 54, 846-854.

24. Brand-Miller JC, Fatema K, Middlemiss C, et al. (2007) Effect of alcoholic beverages on postprandial glycemia and insulinemia in lean, young, healthy adults. Am J Clin Nutr 85, $1545-1551$. 
25. Granfeldt Y, Drews A \& Bjorck I (1995) Arepas made from high amylose corn flour produce favorably low glucose and insulin response in healthy humans. $J$ Nutr 125, 459-465.

26. Behall KM, Hallfrisch JG, Scholfield DJ, et al. (2006) Consumption of both resistant starch and beta-glucan improves postprandial plasma glucose and insulin in women. Diabetes Care 29, 976-981.

27. Park OJ, Kand NE, Chang MJ, et al. (2004) Resistant starch supplementation influences blood lipid concentrations and glucose control in overweight subjects. J Nutr Sci Vitaminol 50, 93-99.

28. Yamada Y, Hosoya S, Nishimura S, et al. (2005) Effect of bread containing resistant starch on postprandial blood glucose levels in humans. Biosci Biotechnol Biochem 69, 559-566.

29. Behall KM \& Hallfrisch J (2002) Plasma glucose and insulin reduction after consumption of breads varying in amylose content. Eur J Clin Nutr 56, 913-920.

30. Le Leu RK, Brown IL, Hu Y, et al. (2003) Effect of resistant starch on genotoxin-induced apoptosis, colonic epithelium, and luminal contents in rats. Carcinogenesis 24, 1347-1352.

31. Li M, Piao JH, Liu QQ, et al. (2008) Effects of the genetically modified rice enriched with resistant starch on large bowel health in rats. Acta Nutr Sin 30, 588-591.

32. Musch MW, Bookstein C, Xie Y, et al. (2001) SCFA increase intestinal $\mathrm{Na}$ absorption by induction of NHE3 in rat colon and human intestinal C2/bbe cells. Am J Physiol Gastrointest Liver Physiol 280, G687-G693.

33. Vernia P, Annese V, Bresci G, et al. (2003) Topical butyrate improves efficacy of 5-ASA in refractory distal ulcerative colitis: results of a multicentre trial. Eur J Clin Invest 33, 244-248.
34. Luhrs H, Gerke T, Schauber J, et al. (2001) Cytokine-activated degradation of inhibitory kappaB protein alpha is inhibited by the short chain fatty acid butyrate. Int J Colorect Dis 16, 195-201.

35. Bauer MM, Florian S, Muller SK, et al. (2006) Dietary resistant starch type 3 prevents tumor induction by 1,2-dimethylhydrazine and alters proliferation, apoptosis and dedifferentiation in rat colon. Carcinogenesis 27, 1849-1859.

36. Dashwood RH, Myzak MC \& Ho E (2006) Dietary HDAC inhibitors: time to rethink weak ligands in cancer chemoprevention? Carcinogenesis 27, 344-349.

37. Mortensen PB \& Clausen MR (1996) Short-chain fatty acids in the human colon: relation to gastrointestinal health and disease. Scand J Gastroenterol Suppl 216, 132-148.

38. Symonds EL, Kritas S, Omari TI, et al. (2004) A combined ${ }^{13} \mathrm{CO}_{2} / \mathrm{H}_{2}$ breath test can be used to assess starch digestion and fermentation in humans. J Nutr 134, 1193-1196.

39. Christian MT, Amarri S, Franchini F, et al. (2002) Modeling ${ }^{13} \mathrm{C}$ breath curves to determine site and extent of starch digestion and fermentation in infants. J Pediatr Gastroenterol Nutr 34, 158-164.

40. Asp ML, Hertzler SR, Chow J, et al. (2006) Gamma-cyclodextrin lowers postprandial glycemia and insulinemia without carbohydrate malabsorption in healthy adults. $J$ Am Coll Nutr 25, 49-55

41. Jenkins DJ, Vuksan V, Kendall CW, et al. (1998) Physiological effects of resistant starches on fecal bulk, short chain fatty acids, blood lipids and glycemic index. J Am Coll Nutr 17, 609-616. 